\title{
O ENSINO DE BIOLOGIA MOLECULAR EM FACULDADES E ESCOLAS MÉDIAS DE SÃO PAULO
}

\author{
Solange Soares Camargo ${ }^{1}$, Maria Elena Infante-Malachias ${ }^{2}$ e José Mariano Amabis ${ }^{3}$ \\ ${ }^{1}$ Bolsista de pós doutoramento do IB/USP com financiamento FAPESP entre os anos de 2000 e \\ 2003. sophia01@uol.com.br \\ ${ }^{2}$ Professora da Escola de Artes, Ciências e Humanidades - EACH- USP marilen@usp.br \\ ${ }^{3}$ Professor do Departamento de Genética e Biologia Evolutiva - IB/USP. Rua do Matão, 277, \\ Cidade Universitária, São Paulo-SP, CEP: 05508-900 amabis@usp.br
}

\section{Resumo:}

O objetivo deste estudo foi avaliar as principais dificuldades do professores, tanto de ensino médio como de ensino superior, na compreensão e interligação de conceitos básicos de Biologia Molecular (BM), além de avaliar também de que maneira tópicos relacionados a este tema, como engenharia genética, alimentos transgênicos e projetos-genoma estão sendo abordados. A finalidade era promover uma discussão inicial sobre a formação de professores que ministram conteúdos desta área, bem como fornecer dados para a elaboração de atividades que favoreçam a ampliação da rede de conhecimentos dos mesmos. Participaram desta pesquisa, realizada entre os anos de 2001 e 2003, 127 professores que responderam a um questionário com 3 seções de 10 perguntas cada. A primeira delas tratou da identificação do entrevistado, a segunda, das concepções sobre BM e a terceira, das concepções sobre Ciência. A análise da primeira seção indicou que grande parte dos entrevistados não teve a disciplina BM durante a sua formação inicial. A segunda seção mostrou que boa parte dos professores apresenta um conhecimento insuficiente, e em alguns casos, inadequado. Assuntos veiculados pela mídia parecem, por este motivo, estar sendo tratados de forma superficial e sem vinculação aos processos celulares implicados. Grande parte dos professores pesquisados parece ter atingido somente os estágios nominal e funcional do processo de alfabetização científica, estando distantes do estágio multidimensional, revelando a necessidade de incluir a disciplina BM nos currículos de graduação, bem como de incentivar programas que visem a educação sobre o genoma.

\begin{abstract}
:
The main objective of this study was to evaluate the difficulties that teachers face, in high school as well as in undergraduate education, with the comprehension and interconnection of basic concepts of Molecular Biology (MB), and also evaluating how issues related to this subject, such as genetic engineering, transgenic foods and genome-projects has been assumed. The research purpose was to explore new strategies that can contribute to enhance the web of knowledge of the teachers, providing them with confidence to apply the referred subject in classroom. The sample survey included 127 teachers; it was carried out between 2001 and 2003. They had to reply to a questionnaire with 3 sections of 10 questions each. The first section asked about the identification of the interviewed; the second inquired about the MB conceptions; and the third section was about the conceptions of Science. The first section's analysis indicated that a significant part of the sample did not have MB during their initial formation. The second section showed that good number of the teachers presented an insufficient, and in some cases, inadequate knowledge. Mass media matters seem, for this reason, to be treated on a superficial way and without linking them to the involved cellular processes. A significant amount of the surveyed teachers seemed to have only reached the phase of nominal and functional in the process of scientific literacy, keeping them distant from the multidimensional phase, which indicates the necessity to include MB as part of the undergraduate programs, as well as to provide programs designed to inform about the genome.
\end{abstract}

Endereço para contato:

* Departamento de Genética e Biologia Evolutiva - IB/USP. Rua do Matão, 277, Cidade Universitária, São PauloSP, CEP: 05508-900 


\section{INTRODUÇÃO}

A Biologia Molecular, entendida como o estudo dos genes a nível molecular é uma ciência relativamente nova. Embora vários estudos anteriores nos aproximem do que hoje sabemos sobre os genes, um destes estudos, e que constitui um marco na Biologia Molecular, foi a elucidação do modelo da dupla-hélice do DNA, realizado por James Watson e Francis Crick [1].

Outro marco importante ocorreu na década de 70 quando os pesquisadores Stanley Cohen e Herbert Boyer conseguiram isolar alguns genes bacterianos e inserilos em plasmídeos, construindo assim os primeiros "cromossomos artificiais" que viriam posteriormente a permitir todo o avanço da genética a nível molecular [2].

Apesar de nova, no entanto, a Biologia molecular é, entre as diversas áreas da Biologia, talvez a que mais se desenvolveu nos últimos anos, principalmente devido aos avanços da genômica e da genética clínica.

Por ter avançado muito, e fazer parte de vários assuntos que cercam o cidadão comum (teste de paternidade, células-tronco, transgênicos, entre outros) este tema mais do que nunca tem chegado às escolas, como podemos verificar em diversos livros didáticos do ensino médio $[3,4,5,6]$ e até mesmo em algumas atividades didáticas destinadas ao ensino fundamental [7].

As informações sobre BM disponíveis na Internet também aumentaram muito. Se há cerca de dez anos os sites relacionados a este assunto eram apenas de instituições especializadas, como o National Institute of Healh - NIH [8] e The Institute Genome for Genomic Research - TIGER [9], atualmente podemos encontrar este assunto nos mais diversos ambientes virtuais: centros clínicos, hospitais e até mesmo em escolas particulares de ensino médio [10, 11, 12].

A despeito do grande avanço da BM e a chegada deste conhecimento à escola muito mais agora do que antes, ele ainda é superficial e carregado de concepções inadequadas, como mostram vários trabalhos apresentados entre os anos de 2001 e 2005 no Congresso Nacional de Genética - Seção Ensino [13].

Concepções inadequadas, relacionadas ao tema BM, também podem ser observadas em diversos trabalhos publicados em outros países $[14,15,16,17,18,19$, 20, 21].

A presença de material genético apenas em células do sangue, genes presentes apenas em gametas e cromossomos como estruturas instáveis, que aparecem e desaparecem durante o processo de divisão celular, são apenas alguns exemplos destas concepções consideradas inadequadas ou cientificamente inválidas [13, $14,15,16,17,18,19,20,21]$.

Concepções cientificamente inválidas parecem paradoxais em nosso país tendo em vista o grande avanço da pesquisa genômica ocorrido nos últimos anos. Desde 1999 que a FAPESP e, sobretudo os pesquisadores brasileiros envolvidos com os projetos-genoma, têm recebido vários prêmios e destaques na mídia, sendo alvo de renomadas revistas internacionais, como New Scientist, Science e Nature [22].

Em julho de 2000, em reportagem de capa sobre a pesquisa realizada no Brasil sobre o genoma da bactéria Xylella, a conceituada revista britânica Nature escreveu um artigo elogiando a participação dos pesquisadores brasileiros. Destacou que o trabalho desenvolvido era "uma conquista não só científica como política", desmentindo "o comum engano de que somente nações industrializadas têm os meios e recursos humanos treinados necessários para fazer ciência de ponta" [23].

Embora esses destaques sejam um estímulo para os pesquisadores brasileiros, o que o artigo não comenta é que os "recursos humanos treinados para fazer ciência de ponta" são uma pequeníssima elite intelectual num país enorme como o nosso. E que o apoio dado em nosso país aos projetos voltados para a educação sobre o genoma é mínimo quando comparada àquele voltado para as pesquisas básicas e aplicadas sobre o genoma.

À diferença do Brasil, nos EUA e demais países que integram o Projeto Genoma 
Humano, boa parte dos recursos é destinada à educação da população, como abordado em [24]. E, importantes materiais instrucionais, voltados para professores, alunos e comunidade em geral são desenvolvidos continuamente, podendo ser obtidos gratuitamente nos sites do National Genome Research Institute [25] do Department of Energy Office of Science [26] e do TIGER - The Institute Genome for Genomic Research [27].

No Brasil, apenas o Centro de Biotecnologia Molecular e Estrutural (CEBM), da USP/São Carlos e o Centro de Estudos do Genoma Humano (CEGH), da USP/São Paulo caracterizam-se como centros de difusão que vem desenvolvendo trabalhos na área de educação sobre o genoma.

O trabalho da Sociedade Brasileira de Genética (SBG) também se destaca, uma vez que nos últimos anos tem incentivado a participação de estudantes e professores no "Genética na Praça", evento que acontece durante o Congresso de Genética. No entanto, acreditamos que estas iniciativas, ainda são poucas para atender a demanda, principalmente de professores e alunos da escola pública.

Além do pouco incentivo dado à educação sobre o genoma, outro fator que contribui para a existência de "concepções inadequadas" ou muitas vezes, ausência de uma rede conceitual cientificamente válida, como definido em [28] parece estar relacionada à maneira como a Biologia é ensinada nas escolas. Ensina-se muito, mas aprende-se pouco. Ou seja, muito conhecimento é lançado no ensino médio, principalmente em função do exame vestibular, mas pouco é, de fato, compreendido [29]. Uma das explicações é que diante de informações excessivas, o aluno prioriza a aprendizagem mecânica em detrimento da aprendizagem significativa. E a aprendizagem mecânica, também chamada de memorização, não permite que o conhecimento se organize em redes, pois ele se perde tão logo é empregado pelo aprendiz.

Para que o conhecimento se organize em redes é essencial que novos conceitos se relacionem a antigos ou previamente conhecidos. Caso contrário, sequer há aprendizagem, pois o "aprender" significa expandir a rede de conhecimentos, portanto, aprendizagem só pode ocorrer a partir do que é previamente conhecido pelo aprendiz [30].

Nos cursos que oferecemos ${ }^{1}$, procuramos sempre investigar os conceitos prévios fundamentais que o professor possui e a partir deles, propor formas de conexão com outros conceitos. Isto porque, se os conceitos fundamentais que deveriam sustentar a rede de conhecimentos inexistem, ou são inadequados, a incorporação de um novo conceito pode também não ocorrer ou ser inadequada [29].

No entanto, ao propormos este levantamento inicial é comum observarmos certa indiferença pelos conceitos ditos "fundamentais ou básicos" e um interesse exagerado por conceitos considerados atuais ou "de ponta". É comum, por exemplo, que o professor queira saber sobre transgênicos e células-tronco, mas não se preocupe em relacionar este conhecimento a conceitos fundamentais, como expressão gênica e diferenciação celular.

A aparente "indiferença" pelos conceitos básicos é verificada também entre alunos de graduação que não apresentam argumentos cientificamente válidos sobre questões de interesse público e social e que se apóiam sobre a Biologia Molecular, como por exemplo, os transgênicos [31].

A incessante busca pelo que é novo parece estar relacionada, pelo menos em parte, ao comportamento da sociedade atual, mencionada em [32] como "sociedade do conhecimento" ou da informação. Segundo o autor, o que há de mais marcante na nossa sociedade é a facilidade com que absorvemos o conhecimento e emitimos

1. "Análise e Reflexão da Prática Pedagógica do Professor de Ciências da Natureza - Módulo I" (2003). "Tópicos Atuais de Genética e Biologia Molecular: O Conhecimento Científico e o Ensino" (2003). "Da Genética a Ética: Propostas para Professores de Biologia" (2002). "Fundamentos do Método Científico e da Biologia Molecular - Módulos I e II" (2001 e 2002). (Cursos de Extensão Universitária oferecidos pelo IB/USP, com duração de 60h cada). 
opinião. No entanto, este conhecimento não pode ser entendido como sinônimo de sabedoria ou aprendizagem. Trata-se de uma superexcitação decorrente de uma ação que não reflete, mas apenas reproduz e opina. "Como se o conhecimento se desse sob a forma de informação, e como se aprender não fosse outra coisa que não adquirir e processar informação." [32, p. 22].

O excesso de informação recebida, junto à necessidade de emitir opinião sobre algum fato, talvez explique, pelo menos em parte, a falta de conexão entre o conhecido e o desconhecido e justifique a superficialidade dos conhecimentos e a rede conceitual cientificamente inválida, como definido em [28].

Agravando o problema da aprendizagem, encontramos ainda no Brasil muitos professores que foram formados antes do avanço da genômica ou que, mesmo sendo formados durante este período, sequer tiveram a disciplina BM inserida no currículo dos cursos de graduação que fizeram, como poderá ser verificado neste trabalho.

Assim, muito do conhecimento que está na mídia e que, deveria ser tratado pelo professor com maior profundidade em sala de aula, acaba não sendo explorado adequadamente ou porque ele não se sente preparado ou porque o tema se encontra no final do livro didático (como foi comentado por alguns professores durante os cursos que ministramos ${ }^{1}$ ).

Uma solução simplista para resolver o problema da Biologia Molecular, pelo menos o da formação inicial do professor, seria um incentivo maior sobre os cursos de atualização, nos quais especialistas seriam contratados para a "transmissão" de conhecimentos novos e a "organização" da confusa rede conceitual.

No entanto, sem conhecer o que o professor já sabe, quais são suas experiências e como ele exerce a docência, tais cursos nada mais representariam do que a repetição do modelo de "transmissão de conhecimentos" sem promover a aprendizagem significativa e sem permitir a inclusão na prática pedagógica do professor, como verificado em alguns estudos [33].

Para atingir tal estado de aprendizagem e inclusão, seria importante aprofundar o conhecimento básico e agrega-lo ao conhecimento atual, estimulando reflexões que tais conhecimentos promovem. De acordo com [34] existem muitas questões de ordem ética, legal e social que poderiam ser trabalhadas a partir de temas como projetos-genoma, testes genéticos e terapia gênica. No entanto, como pode ser visto em [35] "não basta fornecer informações sobre um tema para que este possa ser compreendido e julgado". É necessária a explicação científica, aliada às reflexões políticas e morais que envolveriam estes temas ou "o saber da experiência" na expressão de Bondía [32].

Sendo assim, a nossa intenção com este estudo, é fornecer dados para uma discussão inicial sobre a formação de professores que ministram conteúdos de Biologia Molecular e propor que os cursos oferecidos, ou as disciplinas incluídas nos currículos de graduação, tenham um significado, na definição de Novak [29]. Que os conteúdos possam ser aprendidos de maneira significativa e que sirvam para ampliar a cidadania, tanto do professor como de seus alunos; que sejam incorporados à sua prática e que venham de fato, se constituir em ferramentas das quais o professor possa se apropriar de maneira não-arbitrária e não literal.

\section{Elaboração do instrumento de pesquisa: o questionário}

Para levantamento do perfil do professor, utilizamos como referência os trabalhos de [36]. Para a investigação de concepções alternativas sobre Genética e Biologia Molecular, seguimos os trabalhos de $[14,15,16,17,18,19,20,21]$.

Aspectos mais relacionados ao plano e formato do questionário foram adaptados de [37].

O pré-teste, como sugerido por [38] foi feito com 18 professores, sendo 5 da rede particular de ES (Ensino Superior) e 13 do EM (Ensino Médio), dos quais 9 pertenciam à rede pública e 5 à rede particular. 
Após a análise do pré-teste e reformulação de algumas questões, o questionário foi organizado em 3 seções de 10 perguntas cada: 1a) Identificação do entrevistado; $\left.2^{a}\right)$ Concepção de Biologia Molecular e $3^{a}$ ) Concepção de Ciência. Neste estudo, estaremos nos referindo somente a algumas questões da primeira e da segunda seções, sendo que a terceira (concepção de Ciência) será objeto de outro artigo.

\section{Seleção do grupo amostral}

A seleção dos professores de EM participantes da pesquisa não obedeceu a um critério discriminatório. A divulgação dos $\operatorname{cursos}^{1}$ foi feita via a Comissão de Cultura e Extensão do IB/USP, assim como via algumas Diretorias de Ensino da cidade de São Paulo. Os professores interessados se inscreveram no curso e preencheram 0 questionário, de forma voluntária, no primeiro dia de aula.

Quanto aos professores de ES, foi feito um contato prévio com o coordenador do curso de graduação de Ciências Biológicas. Em seguida, encaminhamos cópias dos questionários e envelopes selados para retorno. Foram contatados 20 coordenadores de Faculdades e Universidades da grande São Paulo, o que representa quase a totalidade das Instituições de Ensino Superior Particular da cidade de São Paulo e imediações nas quais o curso de Ciências Biológicas é oferecido.

De acordo com a solicitação feita por cada Coordenador, foram enviados 2 a 4 questionários por instituição, totalizando 54 questionários. A taxa de retorno dos mesmos foi de 57\%, considerada acima da média esperada [37].

\section{RESULTADOS}

\section{Instituições dos professores pesquisados}

Os 37 professores de ES envolvidos nesta pesquisa foram provenientes de 16 universidades/faculdades de São Paulo (todas da rede particular - Tabela 1). O fato de termos escolhido apenas as instituições de ensino superior particulares foi porque suspeitávamos que a grande maioria dos professores de EM da rede pública haviam se formado nestas instituições. $E$, se pretendíamos um diagnóstico preciso, seria interessante relacionar o educador ao seu educando. Agindo desta forma, esperávamos detectar pontos de difícil compreensão que fossem comuns e propor formas de facilitar a aprendizagem que pudessem ser empregadas para ambas categorias de professores.

Os 90 professores de Biologia do EM participantes desta pesquisa pertenciam a diferentes escolas, sendo a grande maioria $(85,4 \%)$ da rede pública de ensino (Tabela 2). 
Tabela 1 - Relação de questionários avaliados de professores de ES e sua procedência

\begin{tabular}{ll}
\hline Faculdade/Universidade & $\begin{array}{l}\text { Número dequestionários } \\
\text { avaliados }\end{array}$ \\
\hline Centro Universitário Adventista de São Paulo & 2 \\
Centro Universitário São Camilo & 2 \\
Faculdades Integradas Hebraico Brasileira Renascença & 2 \\
Universidade Braz Cubas & 3 \\
Universidade Cidade de São Paulo & 1 \\
Universidade Cruzeiro do Sul & 2 \\
Universidade Ibirapuera & 1 \\
Universidade Metodista de São Paulo & 2 \\
Universidade Presbiteriana Mackenzie & 1 \\
Universidade Santo Amaro & 1 \\
Centro Universitário da Fundação Instituto de Ensino & \\
de Osasco - UniFieo & 1 \\
Centro Universitário Monte Serrat & 2 \\
Faculdade de Filosofia Ciências e Letras de Santo André & 1 \\
Universidade Católica de Santos & 10 \\
Universidade do Grande ABC & 3 \\
Universidade Santa Cecília & 3 \\
TOTAL = 16 Universidades & 37 professores \\
\hline
\end{tabular}

\section{Caracterização do professor}

Os professores de Biologia do ensino médio (EM) envolvidos nesta pesquisa são, na sua grande maioria, mulheres $(78,4 \%)$, formadas há menos de 5 anos $(38,3 \%)$, em curso de Ciências Biológicas $(95,7 \%)$ e em instituições de ensino particular $(83,5 \%)$. Cerca de $50 \%$ não realizaram nenhum curso de pós-graduação e grande parte (74\%) não teve a disciplina Biologia Molecular (BM) incluída no currículo de graduação. Mesmo assim, 68,6\% afirmam trabalhar o tema BM em sala de aula (Tabela 2).

Os professores de ensino superior (ES) se assemelham aos de EM em vários aspectos, embora quase todos ( $97 \%)$ tenham realizado pelo menos um curso de pósgraduação e concluído o curso de graduação há mais tempo que os professores do EM (apenas $8 \%$ se formaram há menor de 5 anos - Tabela 2).

Tabela 2 - Identificação do Entrevistado

\begin{tabular}{l|cc}
\hline & Prof. EM (90) & Prof. ES. (37) \\
\hline Sexo Feminino & $78,4 \%$ & $68 \%$ \\
Idade (31-40) & $36,4 \%$ & $41 \%$ \\
Graduação em Biologia & $95,7 \%$ & $76 \%$ \\
Instituição Particular & $83,5 \%$ & $65 \%$ \\
Formado há menos de 5 anos & $38,3 \%$ & $8 \%$ \\
Não fez pós-graduação & $48,6 \%$ & $3 \%$ \\
Não teve a disciplina BM no currículo de & $73,6 \%$ & $84 \%$ \\
graduação & & $2,7 \%$ \\
Teve a disciplina BM e é formado há menos & $11,7 \%$ & \\
de 5 anos & & $3 \%$ \\
Leciona em Escola Pública & $85,4 \%$ & $76 \%$ \\
Trabalha o tema BM com os alunos & $68,6 \%$ & \\
\hline
\end{tabular}

Obs: O número de professores participantes da pesquisa está entre parênteses. 


\section{Fontes de informação sobre Biologia Molecular}

Questionados onde buscam informação sobre o tema Biologia Molecular, uma vez que não tiveram esta disciplina no currículo, a grande maioria dos professores (de ambas as categorias), aponta outras disciplinas da graduação, como Genética ou Bioquímica (Tabela 3).

Além das disciplinas, as outras fontes de informação, tais como livros, mídia e congressos, são mais indicadas pelos professores de ES. Ou seja, aparentemente esses professores têm mais fontes de informação que os professores de EM, que parecem restritos aos livros e à mídia (Tabela 3 ).

Embora não tenha sido questionada, entre os professores de EM, a natureza dos livros consultados, acreditamos que não se trata de livros de ensino superior e nem específicos da área, uma vez que a maioria não teve a disciplina no currículo de graduação. O que indica, entre outros aspectos, que a fonte de informação para tais professores é muito menos específica e mais limitada.

Tabela 3 - Onde buscam informações sobre o tema Biologia Molecular

\begin{tabular}{l|cc}
\hline & Prof.EM(90) & Prof. ES (37) \\
\hline Outra disciplina & $78,4 \%$ & $56 \%$ \\
Livros & $36,4 \%$ & $46 \%$ \\
Mídia & $23,2 \%$ & $14 \%$ \\
Congressos & $10,4 \%$ & $30 \%$ \\
Pós-graduação & $10,6 \%$ & $26 \%$ \\
\hline
\end{tabular}

Obs: As porcentagens referem-se ao total de professores que escolheram a referida alternativa. Em alguns casos, excede $100 \%$ porque um mesmo professor pode ter escolhido duas ou mais alternativas.

\section{Sobre a compreensão do termo Biologia Molecular}

O uso do termo "Biologia Molecular" como o estudo dos genes a nível molecular, vem sendo empregado por biólogos desde meados da década de 70 . No entanto, para os leigos, tudo aquilo que se refere ao estudo de moléculas, pode ser considerado "Biologia Molecular". Sendo assim, as reações enzimáticas e até mesmo a química passa a ser entendida como tal.

Ao empregarmos duas questões específicas que tratavam do uso deste termo, pretendíamos conhecer melhor o perfil deste professor. Esperávamos que quanto mais o conhecimento do professor se distanciasse do senso comum, mais ele associaria o termo aos processos e técnicas envolvendo o DNA e o dissociaria da "química da célula".

Sendo assim, formulamos a seguinte questão:

5) Assinale, entre os conceitos mencionados abaixo aqueles que lhe vêm à mente quando o tema é "Biologia Molecular".

a.( )Química da célula: átomos, moléculas, energia.

b.( )Algumas estruturas celulares específicas: DNA, RNA, plasmídeos, cromossomos.

c.( ) Alguns processos celulares específicos: replicação, transcrição, tradução.

d.( )Algumas técnicas específicas: PCR, eletroforese, análise de restrição, mapeamento, etc.

e.( ) Assuntos amplamente divulgados pela mídia (genoma, transgênicos, engenharia genética).

A grande maioria dos professores de EM (70,4\%) escolheu a alternativa que 
mencionava algumas estruturas celulares específicas, tais como DNA e RNA. O que indica um certo distanciamento do senso comum. No entanto, quase $40 \%$ destes professores escolheram a alternativa "Química da célula" (Tabela 4).

Tabela 4 - Alternativas relacionadas ao termo "Biologia Molecular" (questão 5)

\begin{tabular}{l|cc}
\hline & Prof. EM(90) & Prof. ES. (37) \\
\hline Química da célula & $39,8 \%$ & $35 \%$ \\
Estruturas celulares específicas & $70,4 \%$ & $73 \%$ \\
Processos celulares específicos & $52,3 \%$ & $76 \%$ \\
Técnicas de Engenharia Genética & $38,6 \%$ & $65 \%$ \\
Assuntos veiculados pela mídia & $58,7 \%$ & $62 \%$ \\
\hline
\end{tabular}

Estes dados nos levam a questionar se o professor que escolheu a alternativa "Química da célula" sabe realmente o significado do termo "Biologia Molecular".

Comparando com os professores de ES, consideramos que os percentuais de ambos são muito semelhantes, com exceção, da alternativa "Técnicas empregadas em Engenharia Genética", a que inferimos seja desconhecida da maioria dos professores de EM, mas, de certa forma, familiar para os professores de ES. A julgar por esses dados, consideramos que uma boa parte dos professores do EM tem noção do que se trata o termo "Biologia Molecular", embora uma parcela significativa também possa incluir neste mesmo conceito tudo que envolve química (Tabela 4).

Entre aqueles que indicam compreender o termo "Biologia Molecular", observase que o professor do EM possui uma visão muito mais morfológica que funcional deste ramo da Biologia (70,4\% desses entrevistados escolheram a alternativa "Estruturas celulares", enquanto 52,3\% escolheram "Processos celulares", tais como replicação e transcrição). O mesmo não acontece para os professores de ES, pois colocaram praticamente no mesmo percentual, tanto as estruturas quanto os processos celulares (73\% contra $76 \%$ - Tabela 4 ).

\section{Assuntos trabalhados em sala de aula e dificuldades apontadas}

Com o intuito de saber quais assuntos o professor trabalha com os seus alunos, e qual o grau de dificuldade encontrado, formulamos as seguintes questões:

7) Assinale, entre os conceitos mencionados abaixo aqueles que você já trabalhou com os seus alunos (podem ser assinaladas mais de uma alternativa).

*foram dadas as mesmas alternativas da questão anterior (5)

8) Assinale, entre os conceitos mencionados abaixo o tema trabalhado com os seus alunos que você achou mais difícil de ensinar (assinale apenas UMA alternativa).

\section{* foram dadas as mesmas alternativas da questão anterior (5)}

Verificamos que o tema mais trabalhado, entre os professores do EM, foi "Estruturas celulares específicas" (69,7\%), seguido de "Química da célula" (57\%) e assuntos veiculados pela mídia (56\%). O tema "Processos celulares" foi o penúltimo tema escolhido por pouco mais de $43 \%$ dos professores. O tema "Técnicas de engenharia genética", praticamente não foi mencionado (7,5\% - Tabela 5$)$. 
Tabela 5 - Tema trabalhado em sala de aula (questão 7)

\begin{tabular}{l|cc}
\hline & Prof. EM (90) & Prof. ES. (37) \\
\hline Química da célula & $57 \%$ & $41 \%$ \\
Estruturas celulares específicas & $69,7 \%$ & $70 \%$ \\
Processos celulares específicos & $43,2 \%$ & $68 \%$ \\
Técnicas de Engenharia Genética & $7,5 \%$ & $43 \%$ \\
Assuntos veiculados pela mídia & $56 \%$ & $59 \%$ \\
\hline
\end{tabular}

Esses dados nos levam a refletir se a Biologia Molecular está sendo adequadamente ensinada na Escola Média. Parece extremamente difícil despertar o lado crítico e levantar questões éticas sobre esses assuntos se a ênfase dada na escola não é sobre os processos biológicos implicados e sim sobre algumas estruturas celulares específicas.

A falta de ênfase sobre o tema "Processos celulares" talvez se explique pelo fato da maioria dos professores pesquisados $(33,1 \%$ - Tabela 6$)$ ter escolhido este tema como o mais difícil de ensinar (questão 8). Se o professor considera difícil ensinar este tema, ele não ensina, e por isso a ênfase no tema "Estruturas celulares" ao invés de "Processos", como vimos na questão 7.

Outro dado interessante é que apenas $11 \%$ dos professores de EM e $3 \%$ dos professores de ES (Tabela 6 ) revelam ter dificuldade para ensinar assuntos divulgados pela mídia. O que nos leva a concluir que esses assuntos devem estar sendo abordados em sala de aula de forma desconectada dos processos celulares implicados, uma vez que o professor tem dificuldade para ensinar tais processos, mas não tem para abordar assuntos da mídia. Provavelmente, o assunto veiculado pela mídia está sendo trabalhado em sala de aula de forma superficial, desconectada dos aspectos biológicos, tal como a mídia os apresenta, o que dificilmente proporcionaria uma reflexão crítica e ética que estes assuntos merecem.

Tabela 6 - Tema mais difícil de ensinar (questão 8)

\begin{tabular}{l|cc}
\hline & Prof. EM (90) & Prof. ES (37) \\
\hline Química da célula & $14,9 \%$ & $3 \%$ \\
Estruturas celulares específicas & $16,8 \%$ & $5 \%$ \\
Processos celulares específicos & $33,1 \%$ & $16 \%$ \\
Técnicas de Engenharia Genética & $6,9 \%$ & $46 \%$ \\
Assuntos veiculados pela mídia & $11,3 \%$ & $3 \%$ \\
\hline
\end{tabular}

\section{DESCONHECIMENTO DE ALGUNS CONCEITOS ESPECÍFICOS DE BM}

A dificuldade para trabalhar o tema "Processos celulares", entre os professores de EM pesquisados, ficou ainda mais evidente quando analisamos a seguinte questão:

Indique o que você sabe sobre cada um dos conceitos identificados por letras, colocando no parêntese correspondente o número de uma das alternativas a seguir:

(1) nunca ouvi nada a respeito.

(2) já ouvi falar, mas não sei exatamente o que significa.

(3) já ouvi falar e considero que sei o significado.
a. ( ) Desnaturação.
f. ( ) Intron/Exon.
b. ( ) Hibridação.
c. ( ) PCR.
d. ( ) Projeto Genoma.
e.( ) Pontes de Hidrogênio.
g. ( ) Operon.
h.( ) Procarioto/Eucarioto.
i. ( ) "Splicing"
j. ( ) Transgênico.
k. ( )Cariótipo. 
Observamos que alguns conceitos diretamente relacionados a processos celulares específicos, tais como "splicing" - relacionado à transcrição e "operon" relacionado ao controle da expressão gênica, são completamente desconhecidos para $43 \%$ e $53 \%$ dos professores de EM pesquisados (Tabela 7). Se este professor nunca ouviu falar a respeito, é provável que esses termos nunca tenham sido abordados nos cursos de graduação que eles fizeram. E, se esses assuntos não foram abordados, dificilmente eles os abordariam com os seus respectivos alunos, explicando assim a ênfase em estruturas celulares ao invés de processos, uma vez que eles não se sentem seguros para explorar um tema sobre o qual não têm conhecimento.

Tabela 7 - Desconhecimento de alguns conceitos específicos de Biologia Molecular (questão 11)

\begin{tabular}{l|cc}
\hline & Prof. EM (90) & Prof. ES (37) \\
\hline PCR & $24,1 \%$ & $6 \%$ \\
Intron/Exon & $41,4 \%$ & $3 \%$ \\
Operon & $43,3 \%$ & $6 \%$ \\
Splicing & $53,5 \%$ & $19 \%$ \\
\hline
\end{tabular}

Com relação aos professores de ES pesquisados, pudemos observar que há um equilíbrio entre os temas "Estruturas celulares" e "Processos" no que se refere aos temas trabalhados em sala de aula (70\% contra $68 \%$ - Tabela 5). O que sugere igual importância na escolha destes temas. No entanto, quanto à dificuldade para trabalhar em sala de aula, o tema mais escolhido por estes professores foi "Técnicas empregadas em Engenharia Genética" (46\% - Tabela 6).

Este dado é de certa forma esperado, uma vez que se o professor de ES não teve a disciplina Biologia Molecular no currículo de graduação, provavelmente desconhece muitas dessas técnicas e realmente tem dificuldade para ensiná-las.

Por outro lado, e do mesmo modo visto para os professores de EM, observamos que muitos dos professores de ES trabalham o tema "Assuntos veiculados pela mídia" em sala de aula (59\% - Tabela 5). No entanto, apenas 3\% (Tabela 6) disseram ter dificuldade para lidar com este tema. O que nos leva a supor que o professor de ES também trabalha assuntos da mídia de forma um tanto quanto superficial. $E$ neste caso, o motivo não seria a dificuldade para abordar os processos celulares implicados, mas o desconhecimento de como se faz, na prática, o que é divulgado na mídia.

Novamente voltamos à questão da dificuldade de se estabelecer um clima propício à reflexão crítica e ética sobre as tecnologias que se apóiam sobre a BM, se a maneira como tais procedimentos são conduzidos é ainda desconhecida por grande parte dos professores, tanto do EM como do ES. A falta de um ensino contextualizado, do ponto de vista da maneira como são feitos os procedimentos laboratoriais, podem contribuir para um conhecimento superficial e pouco reflexivo.

\section{DISCUSSÃO E CONCLUSÃO}

Os professores de Biologia do EM que participaram desta pesquisa são, na sua maioria: biólogos, formados há menos de 5 anos em instituições de ensino particular, sem curso de pós-graduação e sem conhecimento específico na área. Desconhecem, portanto, vários conceitos e técnicas empregadas e apresentam uma visão de Biologia Molecular muito mais morfológica do que funcional. Fato este que se verifica pela ênfase muito maior para o conhecimento das estruturas que compõem a célula do que para os processos com os quais estas estruturas estão envolvidas (Tabelas 4 e 5).

Os professores de ES se assemelham, em vários aspectos, aos professores de EM, com exceção de terem concluído o curso de graduação há mais tempo e realizado um ou mais cursos de pós-graduação (Tabela 2). Além disso, conhecem mais conceitos relacionados à Biologia Molecular que os professores de EM (Tabela 7) e 
apresentam uma visão menos morfológica do que os primeiros (Tabela 5). Apesar disso, conhecem pouco sobre as técnicas empregadas nesta área (Tabela 6) o que pode estar dificultando, tanto a contextualização, como a oferta de um ambiente propício à reflexão e à discussão que tais assuntos poderiam proporcionar.

Quando comparados aos professores do ES, os professores do EM indicam o uso de poucas fontes de informação para estudar os temas de BM (Tabela 3), o que sugere a necessidade da inclusão da disciplina BM nos currículos de graduação, juntamente com a oferta de cursos de atualização que contemplem não somente a parte teórica da BM como também a parte prática.

O fato dos professores do EM não darem muita ênfase a processos, entendidos aqui como, "uma serie de ações ou mudanças sobre algum objeto que resultam em algum efeito" [17] e sim, a certas estruturas celulares (dados que podem ser verificados analisando-se as Tabelas 5 e 7) sugere que assuntos relativos à BM e veiculados pela mídia podem estar sendo abordados de forma superficial, sem propiciar ao aluno a compreensão contextualizada e a capacidade crítica implicados em tais assuntos.

Por outro lado, os dados nos levam a refletir sobre os estágios de alfabetização científica alcançados pelos professores e, seus respectivos alunos, em relação aos conteúdos de Biologia Molecular. Aparentemente estes profissionais conhecem alguns termos científicos e conseguem definir alguns deles, mas não compreendem completamente o seu significado, atingindo apenas os estágios nominal e funcional do processo de alfabetização científica [39].

Ao contrário do que pode supor o senso comum, uma discussão mais ampla dos conteúdos da disciplina Biologia Molecular não serviria apenas para que o aluno se posicionasse a favor ou contra as novas tecnologias advindas dessa área: 0 desenvolvimento de transgênicos, as pesquisas com embriões humanos, a terapia gênica ou os testes genéticos. Ela propiciaria também que os alunos atingissem o estágio multidimensional da alfabetização científica, tendo uma compreensão mais integrada dos conceitos e processos aprendidos e estabelecendo relações entre esse conhecimento e a ciência, a tecnologia e a sociedade.

Krasilchik e Marandino [40] enfatizam a necessidade de atingir o estágio multidimensional:

"É essencial levar o estudante a buscar lógica e racionalmente, e também criticamente, os dados empíricos que devem ser de domínio público. A formação do aprendiz deve levá-lo a compreender que o conhecimento científico é cumulativo e historicamente arquitetado, tendo sempre caráter tentativo. Comporta, por isso, rupturas e está implicado nas relações sociais, políticas, econômicas e ideológicas das sociedades onde é produzido".

Caso o professor tivesse uma melhor formação científica, ele poderia utilizar práticas que saíssem da simples transmissão de conhecimentos, contribuindo assim para que seus alunos desenvolvessem novas estratégias de pensamento e efetivamente pudessem atingir o estágio multidimensional supracitado.

A Lei de Diretrizes e Bases de 1996, com base no estabelecido pela constituição de 1988, define como finalidade da educação básica, o desenvolvimento do educando para o exercício da cidadania, devendo, portanto, fornecer-lhe os meios para progredir no trabalho e em estudos posteriores. Para isso, a necessidade de se repensar a formação inicial dos professores, como vem sendo amplamente discutido no Plano de Formação de Professores da Universidade de São Paulo (PFP-USP) [41].

Não compreender as técnicas que são empregadas na área da BM e não adentrar nos processos celulares que embasam o conhecimento sobre o assunto, como indicam os dados da Tabelas 6 , é desenvolver um estudo descontextualizado e pouco crítico, incompatível com o que é recomendado nos Parâmetros Curriculares 
Nacionais para o Ensino Médio [42] ou o que se espera, de um país expoente da pesquisa genômica.

Sendo assim, consideramos essencial a inserção da disciplina Biologia Molecular, senão em todos os cursos de graduação da área biológica, pelo menos nos de Ciências Biológicas das universidades particulares, que são os principais formadores de professores de Biologia do EM. Como pode ser visto nos resultados, cerca de $96 \%$ dos professores de EM pesquisados se graduaram em Ciências Biológicas e $84 \%$ em instituições particulares de ensino (Tabela 2).

No entanto, mais do que apresentar a disciplina no currículo, é necessário que ela, de fato, exista concretamente. Não devemos criar a disciplina para nos tornar atualizados e para ensinar o que são os componentes celulares e onde eles se localizam. Tais conhecimentos podem (e são) facilmente abordados por outras disciplinas tais como Biologia Celular, Genética ou Bioquímica. No entanto, o aprofundamento sobre os processos e as técnicas, bem como as subseqüentes implicações éticas, legais e sociais advindas deste conhecimento seriam melhor contemplados numa disciplina específica.

Acreditamos que a sociedade atual precisa de professores bem informados que estimulem os seus alunos a desenvolver o pensamento crítico e a reflexão. Sendo assim, a inserção da disciplina BM no currículo, aliada ao incentivo para a educação sobre o genoma, pode ajudar a alcançarmos um outro patamar educativo compatível com aquele já conquistado no campo da pesquisa genômica.

\section{AGRADECIMENTOS}

Agradecemos à FAPESP pela concessão da bolsa de pós-doutoramento, à comissão de cultura e Extensão do IB/USP pela divulgação dos cursos e emissão dos certificados e a todos os professores participantes, sem os quais não teria sido possível a realização deste trabalho.

\section{REFERÊNCIAS BIBLIOGRÁFICAS}

[1] J. Watson e F. Crick (1953). Molecular structure of nucleic acids - a structure for deoxyrribose nucleic acid. Nature, 171, 77-738

[2] S.N. Cohen, A.C.Y Chang, H.W Boyer e R.B Helling (1973). Construction of biologically functional bacterial plasmids in vitro. Proceedings National Academy of Science, 70,3240-3244

[3] J.M. Amabis e G. Martho (2001). Conceitos de Biologia - genética evolução e ecologia São Paulo: Editora Moderna

[4] A. Gainotti e A. Modelli (2002). Biologia para o ensino médio, volume único, série parâmetros, São Paulo: Editora Scipione

[5] A. Uzuniane e E. Birner (2003). Biologia, volume único, São Paulo: Editora Harbra

[6] S. Linhares e F. Gewandsznajder . Biologia - Série Brasil, Volume único, São Paulo: Editora Ática

[7] Revista Ciência Hoje na Escola < $\underline{\text { http://www.cienciahoje.uol.com.br }>~}$

[8] National Institute of Health < $\underline{\text { http://www.nih.gov }>}$

[9] The Institute Genome for Genomic Research <http://www.tigr.org > 
[10] Genesis - Laboratório de Diagnóstico em Biologia Molecular <http://educacao.genesisdbm.com.br/>

[11] Laboratório Gene - Núcleo de Genética Médica <http://www.gene.com.br>

[12] Unifesp virtual <http://www.virtual.epm.br>

[13] Trabalhos apresentados entre os anos de 2001 e 2005 no Congresso Nacional de Genética - Seção Ensino <http://www.sbg.org.br>

[14] H.H. Cho J.B. Kahle e F.H. Nordland (1985). An investigation of high school biology textbooks as sources of misconceptions and difficulties in genetics and some suggestions for teaching genetics. Science Education, 69, 5, 707-719

[15] F.E.G. Cox. (1989).Molecular Biology in schools, higher education, and afterwards. Journal of Biological Education, 23, 1, 9-11

[16] M.U. Smith (1991). Teaching cell division: student difficulties and teaching recommendation. Journal of the College Science Teaching, 21, 1, 28-33

[17] A.C.H. Kindfield (1994). Understanding a basic biological process: expert and novice models of meiosis. Science Education, 78, 3, 255-283

[18] C. Wood-Robinson, J. Lewis, J. Leach e R. Driver (1998). Genética y formación científica: resultados de un proyecto de investigación y sus implicaciones sobre los programas escolares y la enseñanza. Enseñanza de las Ciencias, 16, 1, 43-61

[19] E. Banet e E. Ayuso (2000). Teaching genetics at secondary school: a strategy for teaching about localization of inheritance information. Science Education, 84, 3, 313-351

[20] J. Lewis, J. Leach e C. Wood-Robinson (2000). All in the genes? - Young people's understanding of the nature of genes. Journal of Biological Education, 34, 2, 74-79

[21] J. Lewis, J. Leach e C. Wood-Robinson (2000). Chromosomes: the missing link young people's understanding of mitosis, meiosis and fertilization. Journal of Biological Education, 34, 4, 189-199

[22] FAPESP Genoma - ONSA in the press

$<$ http://watson.fapesp.br/imprensa/press.htm $>$

[23] C. Macilwain e R. Bonalume Neto (2000). News Feature - A springboard to success. Nature, 407, 440

[24] M. Munn, P.O. Skinner, L. Conn, H.G Horsma e P. Gregory (1999). The Involvement of Genome Researchers in High School Science Education - Review. Genome Research: 9, 7, 597-607

[25] National Genome Research Institute < http://www.genome.gov/Education>,

[26]Human Genome Project Information - Department of Energy Office of Science <http://www.ornl.gov/sci/techresources/Human_Genome/home.shtml > 
[27] The Institute Genome for Genomic Research < http://www.tigr.org/edutraining/>

[28] I. R. Galagovsky (1996). Redes conceptuales - aprendizaje, comunicación y memoria. Buenos Aires: Lugar Editorial

[29] J. D. Novak (2002). Meaningful learning: the essential factor for conceptual change in limited or inappropriate propositional hierarchies leading to empowerment of learners. Science Education, 89, 4, 548-571

[30] D. P. Ausubel (1963). The psychology of meaningful verbal learning. New York: Grune and Stratton

[31] M. E. Infante-Malachias, S.S. Camargo, J.M. Amabis (2006). Alimentos Transgênicos: Opinião de Alunos Universitários. Em preparação.

[32] J. L. Bondía (2002). Notas sobre a experiência e o saber da experiência. Revista Brasileira de Educação, 19, 20-28

[33] S.F. Trivelato (1987) Ensino de genética em uma escola de segundo grau. São Paulo,. Tese (Mestrado) - Faculdade de Educação da USP

[34] M. A. Cutter, E. Drexler, B.E Friedman, L.B McCullog, J.D. McInerty, J., B., Murrayrossiter, J. Zola (1997) The puzzle of inheritance: genetics and the methods of science - Biological Sciences Curriculum Study (BSCS) - Colorado, EUA

[35] S.F Trivelato (1993) Ciência, tecnologia, sociedade: mudanças curriculares e formação de professores. São Paulo. Tese (Doutorado) - Faculdade de Educação da USP

[36] M. Krasilchik (1972) Ensino de biologia em São Paulo: fases de renovação. São Paulo, 184p. Tese (Doutorado) - Faculdade de Educação da USP

[37] J.F Rummel (1977) Introdução aos procedimentos de pesquisa em educação. Rio de Janeiro: Ed. Globo

[38] L Rampazzo (1998). Metodologia Científica para alunos de graduação e pósgraduação. Lorena: Ed. Siciliano

[39] BIOLOGICAL SCIENCE CURRICULUM STUDY - BSCS (1993). Developing Biological Literacy. Colorado, EUA

[40] M. Krasilchik, e M. Marandino (2004) Ensino de Ciência e Cidadania. São Paulo: Moderna

[41] PFP-USP (2004). Programa de Formação de Professores. Comissão Permanente de Licenciaturas. Pró-Reitoria de Graduação. 37 pp

[42] Brasil (1999). Parâmetros Curriculares Nacionais para o Ensino Médio: Ciências da Natureza, Matemática e suas Tecnologias. 